\title{
KEMAMPUAN BERPIKIR REFLEKTIF DALAM PRAKTIK PEMBELAJARAN MATEMATIKA BERBASIS PROJECT LESSON STUDY
}

\author{
Flavia Aurelia Hidajat ${ }^{1)}$ \\ ${ }^{1)}$ Universitas Panca Marga, Jalan Yos Sudarso No.107, Probolinggo; \\ flaviadorothea@gmail.com
}

Received : $19 / 10 / 2019$

Accepted : 29/01/2020

Published : $31 / 01 / 2020$

\begin{abstract}
The learning practices based on Project of Lesson Study in this research consist of three stages, namely planning (Plan) which is described in the lesson plan, implementation (Do) which is described in the lecturer's actions in conducting RRP planning, and observation (See) which consists of observing learning activities and activities reflect action. Reflection is an important activity that leads to the determination of the next improvement. Through this reflection activity, a person needs to have the ability to think reflectively. The purpose of this research is to describe the reflective thinking skills of prospective mathematics lecturers in learning practices based on Project Lesson Study. This study involved 12 prospective mathematics education lecturers who are PPL students at the University in Malang. Data analysis was performed in three ways, namely reducing rough data from research, presenting data, and drawing conclusions descriptively. The results showed that (1) the ability to think refletively of prospective mathematics lecturers increased after learning practices based on project lesson study; (2) this reflective thinking ability helps improve learning and interaction between lecturers and students and students and students; (3) reflection activities in learning practices based on project lesson study collectively can develop reflective thinking skills of the prospective lecturer.
\end{abstract}

Keywords: Reflective thinking skills, Reflection, Project of lesson study.

\begin{abstract}
Abstrak
Praktik pembelajaran berbasis Project Lesson Study dalam penelitian ini terdiri atas tiga tahapan, yaitu Perencanaan (Plan) yang terdeskripsi dalam RPP, pelaksaaan (Do) yang terdeskripsi dalam tindakan dosen dalam melaksanaan perencanaan RRP, serta observasi (See) yang terdiri atas kegiatan observasi pelaksanaan pembelajaran dan kegiatan merefleksikan tindakan. Refleksi merupakan kegiatan penting yang mengarah pada penentuan perbaikan berikutnya. Melalui aktivitas refleksi ini, seseorang perlu memiliki kemampuan untuk berpikir reflektif. Tujuan dari penelitian ini adalah mendeskripsikan kemampuan berpikir reflektif calon dosen matematika dalam praktik pembelajaran berbasis Project Lesson Study. Penelitian ini melibatkan 12 calon dosen pendidikan matematika yang merupakan mahasiwa PPL pada Universitas di Malang. Analisis data dilakukan dengan tiga cara, yakni mereduksi data kasar dari penelitian, menyajikan data, dan menarik kesimpulan secara deskriptif. Hasil penelitian menunjukkan bahwa (1) kemampuan berpikir refletif dari para calon dosen matematika meningkat setelah praktik pembelajaran berbasis project lesson study; (2) kemampuan berpikir reflektif ini membantu meningkatkan pembelajaran serta interaksi antara dosen dengan mahasiswa dan mahasiswa dengan mahasiswa; (3) aktivitas refleksi dalam praktik pembelajaran berbasis project lesson study secara kolektif dapat mengembangkan kemampuan berpikir reflektif dari calon dosen tersebut.
\end{abstract}

Kata Kunci: Kemampuan berpikir reflektif, Refleksi, Project lesson study 


\section{Pendahuluan}

Besarnya potensi dari peran calon dosen pada setiap peningkatan mutu dan kualitas dari pendidikan, memberikan suatu alarm bagi masyarakat bahwa mutu dan kualitas profesionalisme dari seorang calon dosen harus diperhatikan dan ditingkatkan secara terus menerus. Peningkatan profesionalisme mutu dan kualitas seorang dosen ini harus didasarkan pada proses pembelajaran yang dapat bermakna bagi mahasiswa (Sukaesih and Alimah, 2012). Pembelajaran bermakna merupakan pembelajaran yang tersusun secara sistematis, teratur, dan terencana yang terfokus pada konstruksi atau pembangunan pengetahuan baru dari pengaitan pengetahuan-pengetahuan lama, sehingga mahasiswa memahami materi lebih mendalam, lebih dari sekedar tahu, mampu menginternalisasikan pengetahuan pada dirinya, sehingga mahasiswa dapat membentuk suatu karakter yang baik dalam menerima dan membangun ilmu baru (Subanji, 2013).

Agar aktivitas untuk mempercepat pelaksanaan pembelajaran bermakna ini terwujud, para calon dosen perlu melakukan tiga tahapan dalam suatu praktik pembelajaran di kelas, yaitu perencanaan (plan), pelaksanaan (do) dan observasi dan refleksi (see) (Mitasari and Prasetiyo, 2016). Tahapan proses secara siklik ini disebut dengan suatu project lesson study, dimana lesson study ini digunakan untuk peningkatan profesionalisme dari para pendidik (Almujab et al., 2018). Pada praktik lesson study ini, tahap refleksi merupakan kunci utama yang penting dalam suatu praktik pembelajaran yang bermakna. Aktivitas refleksi dalam praktik pembelajaran memiliki peran yang besar untuk perbaikan praktik pembelajaran berikutnya. Ketika seseorang secara kritis melakukan proses refleksi, maka mereka semakin berkesempatan untuk merencakan kembali strategi pembelajaran sehingga praktik pembelajaran yang tercipta sangat bermakna. Sebaliknya, ketika seseorang tidak melakukan refleksi pada semua tindakannya, maka pembelajaran bermakna yang diinginkannya tidak akan tercipta sesuai keinginannya. Agar setiap orang dapat melakukan aktivitas dari proses refleksi yang bermutu baik dan berkualitas, maka Ia juga perlu mempunyai kemampuan dari berpikir reflektif.

Berpikir reflektif merupakan proses mental yang mengarah pada kesadaran mengenai sesuatu hal yang diketahui ataupun dibutuhkan untuk menjembatani kesenjangan dari suatu kondisi/situasi belajar (Choy and Oo, 2012). Pada aktivitas refleksi dalam praktik pembelajaran berbasis project lesson study, para calon dosen harus difokuskan pada kegiatan menganalisis, mengevaluasi, dan mencari makna dari suatu konsep secara mendalam agar mereka menemukan hal-hal yang menjadi bahan perbaikan/revisi untuk didibahas secara bersama dengan para calon dosen lainnya dan dosen yang sesungguhnya (dosen senior). Oleh karena itu, aktivitas refleksi ini dapat menuntun dan memberikan kesadaran pada para calon 
dosen untuk melaksanakan praktik pembelajaran yang bermakna. Hal ini sesuai dengan pendapat (Gurol, 2011), yakni berpikir reflektif dapat membantu dan menuntun seseorang secara terarah, sistematis, dan tepat untuk menyadari, menganalisis, memotivasi, mengevaluasi, dan memperoleh makna dari suatu konsep yang mendalam.

Hidajat et al. (2019) menjelaskan bahwa berpikir reflektif dapat menciptakan informasi baru, menetapkan keputusan kesimpulan yang tepat, dan menilai informasi dengan benar terkait proses pemahaman konsep dalam kehidupan sehari-hari. Dalam praktik project lesson study, aktivitas refleksi dilaksanakan secara nyata dalam praktik pembelajaran. Oleh karena itu, aktivitas refleksi bukan hanya berdasarkan pada batasan teori, namun melibatkan faktafakta secara real dalam suatu masalah dalam praktik pembelajaran agar tercipta praktik pembelajaran bermakna. Dengan kata lain, jika seseorang melakukan aktivitas refleksi pada dirinya secara terus menerus dalam praktik project lesson study, maka mereka secara tidak langsung mengasah kemampuan berpikir reflektifnya.

Menurut Zehavi and Mann (2005), berpikir reflektif merupakan proses mental yang menfokuskan seseorang untuk memanggil pengetahuan sebelumnya dan menggunakannya melalui proses penyelidikan dalam mengatasi masalah matematika. Lee (2005) menyebutkan bahwa komponen-komponen terpenting dalam berpikir reflektif yaitu recall, rationalization, reflectivity. Recall merupakan suatu aktivitas yang terfokus pada proses mendeskripsikan apa yang dialami seseorang, menimbang, dan menafsirkan suatu kondisi sesuai dengan pengalamannya, dan mengamati dari setiap tindakan yang dilakukannya. Aktivitas refleksi dalam praktik pembelajaran berbasis project lesson study dimulai dari observasi keigiatan pembelajaran, mengenal kondisi masalah yang terjadi di kelas, mendeskripsikan masalah dalam kegiatan praktik pembelajaran di kelas, serta membandingkan masalah tersebut dengan informasi yang dimiliki untuk proses perencanaan.

Pada aktivitas rationalization, seseorang mulai menghubungkan antara pengalaman sebelumnya dan praktik pembelajaran yang dihadapi, menganalisis dan menginterpretasikan kondisi sesuai hal-hal yang rasional, serta menggeneralisasi observasi dari praktik pembelajaran sesuai dengan hasil pengolahan data berdasarkan penalarannya. Aktivitas rationalization dalam praktik pembelajaran berbasis project lesson study cenderung pada tindakan para calon dosen untuk mengobservasi sekaligus membandingkan dengan praktik pembelajaran yang ideal sesuai rencana denagn pengalaman dalam praktik yang telah di alami, sehingga aktivitas ini dapat di gunakan untuk membentuk suatu kesimpulan berdasarkan kesesuaian ataupun ketidaksesuaian praktik pembelajaran yang di inginkan.

Pada aktivitas reflectivity ini, seseorang menelusuri segala hal yang telah dilakukan, menimbang, membandingkan antara praktik-praktik pembelajaran yang telah diobservasinya, 
pengalaman yang telah dimiliki dan situasi kondisional yang ideal sesuai yang diinginkan, serta menganalisis kondisional yang dialami tersebut dalam berbagai perspektif pandangan yang baru. Untuk kegiatan lesson study, para calon dosen mengobservasi dan menangkap semua kondisi praktik pembelajaran secara nyata dan real. Pada kondisi ini, para calon dosen harus mengontrol dan menganalisis situasi kondisional praktik pembelajaran sekaligus memunculkan interaksi antara dosen dengan mahasiswa, ataupun mahasiswa dengan mahasiswa. Pada situasi kondisional yang nyata dan real ini dideskripsikan untuk menganalisis keberhasilan serta kegagalan, dimana kegagalan ini dapat menjadi perbaikan untuk praktik pembelajaran ke depan melalui rencana yang baru.

\section{Metode Penelitian}

Subjek dalam penelitian ini adalah 12 calon dosen pendidikan matematika yang merupakan mahasiwa PPL pada salah satu Universitas di Malang. Pada penelitian ini, satu calon dosen melakukan pelaksanaan (Do) dan 11 calon dosen lainnya menjadi obsever, sehingga aktivitas penelitian ini dilakukan secara bergantian. Oleh karena itu, metode untuk pengambilan data pada penelitian ini dilaksanakan melalui observasi berjenis partisipatif.

Data dari 12 subjek berupa rekaman hasil reflektif dan catatan observasi. Analisis data dilakukan dengan tiga cara, yakni mereduksi data kasar dari penelitian, menyajikan data, dan menarik kesimpulan secara deskriptif. Data yang dianalisis dan disajikan dalam bentuk deskriptif kualitatif tersebut didasarkan pada komponen-komponen dalam berpikir reflektif dari Lee (2005), yakni komponen recall, komponen rationalization, dan reflectivity. Data yang direcall dalam praktik pembelajaran sebelumnya yang dilakukan oleh dosen sebenarnya (dosen senior) atau bukan real teaching. Data kemudian disajikan dan diterapkan dalam tahap rationalization, dimana praktik pembelajaran berbasis project lesson study bisa terdeskripsikan secara bermakna dan mendalam bagi pelajar (mahasiswa). Sedangkan, data yang terdeskripsikan dalam tahap reflectivity adalah lima praktik dari proses refleksi yang dilaksanakan secara kolektif oleh 12 calon dosen dan satu dosen kelas yang sebenarnya (dosen senior) dalam praktik pada aktivitas project lesson study.

\section{Hasil dan Pembahasan}

Kemampuan berpikir reflektif mahasiswa dalam praktik pembelajaran berbasis project lesson study didasarkan pada komponen berpikir reflektif dari Lee (2005), yakni recall, recall, rationalization, dan reflectivity. Pada praktik pembelajaran berbasis project lesson study, Recall tertuju pada aktivitas menyusun perencanaan (PLAN) untuk praktik pembelajaran di kelas yang akan dilakukan oleh calon dosen kelas. Rationalization tertuju pada aktivitas pelaksanaan dari rencana yang telah ditetapkan, mengobservasi dan menangkap hasil dari 
setiap observasi dalam praktik pembelajaran berbasis project lesson study. Reflectivity tertuju pada proses refleksi setelah praktik pembelajaran berlangsung.

\subsection{Aktivitas Recall Sebagai Tahap "PLAN" dalam Project Lesson Study}

Pada proses perencanaan praktik pembelajaran berbasis Project Lesson Study, 12 calon dosen secara kolektif melakukan dua kegiatan utama, yaitu melakukan observasi awal dalam praktik pembelajaran di kelas dan melaksanakan perencanaan (PLAN) untuk pelaksanaan (DO) praktik pembelajaran berbasis projectlesson study. poin satu

\subsubsection{Observasi Awal}

Observasi dilaksanakan sebanyak lima kali pertemuan. Obsever (11 para calon dosen lainnya) secara bersama-sama mengamati praktik pembelajaran yang dilakukan oleh dosen kelas yang sebenarnya (dosen senior). Praktik pembelajaran diawali pada suatu salam pembuka, pengerjaan soal latihan dan menuliskan pengerjaan soal tersebut di papan tulis, serta kemudian dilakukan pembahasan hasil pekerjaan mahasiswa tersebut. Aktivitas pada observasi ini bertujuan untuk mengamati segala proses dalam praktik pembelajaran dan menjadikannya sebagai bahan referensi untuk melakukan perencanaan (PLAN).

\subsubsection{Perencanaan (PLAN)}

Aktivitas yang dilakukan antara lain menetapkan materi dengan dosen kelas yang sebenarnya (dosen senior), yaitu materi tentang logika, kemudian menyusun rencana pelaksanaan pembelajaran (RPP) secara bersama-sama dalam kelompok para calon dosen, dan menyiapkan materi logika ke dalam bentuk power point. Dosen kelas yang sebenarnya (dosen senior) memberikan saran terhadap RPP dan materi yang telah disusun oleh kelompok dari para calon dosen. Berdasarkan perencanaan tersebut, dua belas calon dosen sebagai model secara bergantian melaksanakan praktik pembelajaran berbasis project lesson study sesuai dengan RPP yang telah disusun. Berdasarkan hasil diskusi tersebut, praktik pembelajaran akan dilakukan sebanyak dua kali pertemuan. Pertemuan pertama adalah penyampaian materi, pembentukan kelompok, dan diskusi antar mahasiswa. Sedangkan, pertemuan kedua adalah dan antar kelompok, penarikan kesimpulan, dan latihan soal.

Kegiatan berikutnya adalah kegiatan peer teaching. Keduabelas para calon dosen secara bergantian menjadi model untuk melakukan praktik pembelajaran sesuai dengan RPP yang telah disusun. Saat salah satu calon dosen menjadi dosen model, para calon dosen lainnya berperan menjadi pelajar (mahasiswa). Para calon dosen lainnya yang berperan menjadi mahasiswa ikut memberikan comment, kritik, dan saran serta bertanya untuk 
mengantisipasi pertanyaan yang muncul dari mahasiswa saat praktik pembelajaran berbasis project lesson study berlangsung nantinya. Tujuan kegiatan peer teaching adalah agar para calon dosen lancar dalam menyampaikan materi untuk praktik pembelajaran berbasis project lesson study berikutnya. Pada akhir pelaksanaan peer teaching, kegiatan refleksi bertujuan untuk memperbaiki perencanaan praktek pembelajaran di kelas

Pada aktivitas perencanaan praktik pembelajaran, subjek memanggil dan menggunakan pengalaman yang dimiliki sebelumnya (recall) untuk membuat, menyusun dan menetapkan rencana pelaksanaan praktik pembelajaran berbasis project lesson study yang terbaik. Proses mengemukakan pengalaman yang dimiliki oleh subjek mengakibatkan Ia mencoba untuk membuat suatu ide yang inovasi dan kreatif dalam suatu rencana praktik pembelajaran berbasis project lesson study. Rencana praktik pembelajaran berbasis project lesson study ini selanjutnya dilakukan oleh 12 subjek yang terbagi dalam 6 kelompok dengan karakteristik yang sama namun materi yang berbeda. Rencana praktik pembelajaran ini terfokus pada pembelajaran yang bermakna, menyenangkan, namun tetap berfokus pada materi yang akan diajarkan. Pada tahp ini, subjek mengaitkan setiap perencanaan, praktik pembelajaran sebelumnya, observasi dari pengalaman sebelumnya, dan teori praktik pembelajaran untuk menciptaakan pembelajaran bermakna. Pada proses merancang rencana praktik pembelajaran, subjek memanggil serta menggunakan kembali pengalaman dari praktik sebelumnya dan mengkoordinasikannya berdasarkan praktik pembelajaran yang bermakna dan tidak bermakna. Oleh karena itu, subjek bisa membuat rencana praktik pembelajaran berbasis project lesson study yang sangat bermakna bagi mahasiswa dengan memanggil (recall) dari pengelaman praktik sebelumnya berdasarkan materi.

\subsection{Aktivitas Rationalization Sebagai Tahap "DO" dalam Project Lesson Study}

Pada aktivitas rationalization, praktik pembelajaran dimulai dengan adanya pertanyaan motivasi terkait pertanyaan singkat untuk semua mahasiswa agar mereka mengingat kembali materi ekivalensi secara logika pada pertemuan sebelumnya. Dosen model memberikan kesempatan mahasiswa dalam menjawab pertanyaan motivasi dengan menunjuk mahasiswa yang kurang aktif. Beberapa mahasiswa memberikan respon yang baik dan sesuai dengan RPP yang telah disusun. Mahasiswa mampu mengingat kembali materi tentang ekivalen secara logika dengan menjawab definisi ekivalensi secara logika. Dosen kemudian memberikan respon atas respon baik yang diberikan oleh mahasiswa dengan memberikan permasalahan yang berkaitan dengan ekivalen secara logika. Dosen model juga meminta perwakilan mahasiswa untuk menuliskan jawabannya dipapan tulis, sedangkan mahasiswa lainnya diminta untuk menyelesaikan permasalahan berikutnya. Kegiatan pembelajaran ini bertujuan 
untuk mengingatkan kembali dan memahami materi yang berkaitan dengan ekivalen secara logika pada mahasiswa.

Kegiatan selanjutnya adalah mengarahkan mahasiswa dari permasalahan yang telah dikerjakan sebelumnya dengan definisi kontraposisi, konvers, dan invers. Mahasiswa mencoba memahami mengenai definisi kontraposisi, konvers, dan invers. Dosen kemudian memberikan pertanyaan arahan, yaitu:

“Apakah kontraposisi dan proposisi awal merupakan ekivalensi secara logika? apakah kontraposisi dan konvers suatu proposisi merupakan ekivalensi secara logika? apakah kontraposisi dan invers suatu proposisi merupakan ekivalensi secara logika? dan apakah konvers dan invers suatu proposisi merupakan ekivalensi secara logika?".

Mahasiswa mendiskusikan pertanyaan arahan tersebut dengan mahasiswa lainnya dan mencoba untuk menjawab pertanyaan tersebut dengan menggunakan tabel kebenaran. Kegiatan pembelajaran ini bertujuan untuk mengenalkan mahamahasiswa mengenai definisi kontraposisi, konvers dan invers.

Dosen kemudian memberikan permasalahan yang berkaitan dengan definisi kontraposisi, konvers, dan invers. Subjek mendiskusikan dengan teman sejawat lainnya dan mengerjakan permasalahan tersebut. Calon dosen kemudian menunjuk beberapa nama mahasiswa untuk menuliskan jawabannya di depan kelas, sedangkan mahasiswa lainnya diminta untuk menyelesaikan permasalahan berikutnya. Pada kegiatan ini, mahasiswa memberikan respon yang baik terhadap permasalahan yang diberikan dengan mengacungkan tangan untuk maju dan mempresentasikan hasil pekerjaannya tersebut di depan kelas. Dosen selanjutnya mengarahkan mahasiswa untuk membandingkan kebenaran jawaban mahasiswa secara logika dengan tabel kebenaran yang telah dibuat. Kegiatan pembelajaran ini bertujuan untuk memahamkan mahasiswa mengenai definisi kontraposisi, konvers dan invers. Pada akhir pembelajaran, mahasiswa diberikan tugas rumah.

Berdasarkan tahap pelaksanaan (DO), praktik pembelajaran juga di amaiti oleh obsever untuk perbaikan pada praktik berikutnya. Kedua belas subjek melakukan observasi pada setiap pelaksanaan (DO) yang telah didasarkan rencana praktik pembelajaran yang telah dibuat pada tahap selanjutnya. Pada tahap pelaksanaan ini, subjek mengaitkan setiap perencanaan, menggunakan metode sesuai rencana yakni diskusi dan berintaraksi anatar dosen dengan mahasiswa ataupun menciptakan interaksi antara mahasiswa dnegan mahasiswa. Selain itu, subjek juga menganalisis dan mengati setiap kekurangan yang telah dilakukan dan kelebihan yang belum di lakukan. 


\subsection{Aktivitas Reflectivity Sebagai Tahap "DO" dalam Project Lesson Study}

Aktivitas refleksi dilaksanakan pasca selesainya praktik dari pembelajaran yang dilaksanakan secara kolektif antara dosen model (para calon dosen), dosen yang sebenarnya (dosen senior), obsever, dan peneliti. Pada tahap ini, obsever menunjukkan hasil pengamatan yang mengandung kelebihan dan kekurangan selama aktivitas rationalization pada tahap pelaksanaan (DO). Hasil pengamatan ini didiskusikan, kemudian mereka mengaitkan dan mencari kekurangan ataupun kelebihan dalam praktik pembelajaran sebelumnya yang tidak sesuai dengan rencana yang diinginkan ataupun kekurangan calon dosen akibat dari rencana pembelajaran yang salah. Dua belas subjek penelitian juga melakukan aktivotas refleksi pada tahap ini. Mereka mengemukakan setiap fakta real yang dialami selama pelaksanaan praktik pembelajaran di kelas, membandingkan setiap fakta real tersebut dengan rencana kondisi ideal yang diinginkan, membuat perbaikan rencana dengan memperhatikan setiap kekuarang dari praktk sebelumnya.

Sebagai contoh pada awal pembelajaran, mahasiswa siap dengan pembelajaran yang akan dilakukan. Mahasiswa juga memberikan respon yang selalu baik selama pembeljaran berlangsung. Kegiatan pembelajaran dikelas juga hampir sesuai dengan rencana pelaksanaan pembelajaran yang telah disusun sebelumnya. Namun, alokasi waktu pada kegitaan pembelajaran tidak sesuai dengan alokasi waktu pada rencana praktik pembelajaran yang telah disusun sebelumnya. Hal ini terjadi ketika dosen model memberikan pertanyaan arahan untuk mengenal definisi kontraposisi, konvers dan invers. Mahasiswa menjawab dan membuktikan pertanyaan-pertanyaan tersebut dengan membuat tabel kebenaran secara individu untuk setiap pertanyaannya. Dosen model juga tidak membatasi waktu pengerjaan mahasiswa di papan tulis dengan menjadikan satu tabel kebenaran untuk semua pertanyaan. Berdasarkan refleksi pada pembelajaran ini, dosen model memperbaiki rencana praktik pembelajaran pada pertemuan berikutnya dengan menambahkan materi teorema-teorema proposisi kondisional dan bikondisional serta kemudian di lanjutkan pemberian latihan soal. Kesadaran dan ketajaman subjek dalam mengamati, mengkritis, dan menganalisis hasil pengamatan, subjek menemukan suatu hasil yang menunjukkan adanya kemampuan berpikir reflektif pada mahasiswa. Kekritisan untuk berpikir reflektif dari 12 orang subjek penelitian meningkat dan berkembang seiring dengan praktik pembeljaran berbasis project lesson study. Berdasarkan uraian diatas, aktivitas refleksi dalam praktik project lesson study ini berkontribusi dalamsetiap peningkatan dan pengembangan kemapuan berpikir reflektif dari setiap para calon dosen (mahasiswa) sekaligus meningkatkan profesionalisme calon dosen untuk mempersiapkan praktik pembelajaran berikutnya. Kondisi terjadi karena aktivitas dalam 
project lesson study ini merefleksikan pengalaman praktik sebelumnya untuk meningkatan praktik pembelajaran berikutnya yang lebih baik dan bermakna bagi mahasiswa.

\section{Kesimpulan}

Kemampuan berpikir reflektif dari para calon dosen matematika meningkat setelah praktik pembelajaran berbasis project lesson study. Kemampuan berpikir reflektif ini membantu meningkatkan pembelajaran serta interaksi antara dosen dengan mahasiswa dan mahasiswa dengan mahasiswa. Aktivitas refleksi dalam praktik pembelajaran berbasis project lesson study secara kolektif dapat mengembangkan kemampuan berpikir reflektif dari calon dosen tersebut. Kondisi ini terjadi di akibatkan karena para calon dosen saling memabantu, mengobservasi, dan belajar untuk berkreasi dalam meningkatkan praktik pembelajaran di kelas.

\section{Saran}

Aktivitas praktik pembelajaran berbasis project lesson study sebaiknya perlu dilakukan oleh para pendidik di sekolah ataupun perdosenan tinggi, sehingga praktik pembelajaran dapat meningkat dan berkembang lebih baik dan menjadi pembelajaran bermakna bagi pelajar (mahasiswa ataupun siswa).

\section{Pustaka}

Almujab, S. et al. (2018) 'Penerapan Lesson Study Melalui Metode Project Based Learning Untuk Meningkatkan Keaktifan Mahasiswa Dalam Proses Pembelajaran Di Fkip Unpas', Jurnal Refleksi Edukatika, 8(2), pp. 139-148. doi: 10.24176/re.v8i2.2352.

Choy, S. C. and Oo, P. S. (2012) 'Reflective Thinking and Teaching Practices: a Precursor for Incorporating Critical Thinking Into the Classroom?', International Journal of Instruction, 5(1), pp. 167-182.

Daryanto (2013) Inovasi Pembelajaran Efektif. Bandung: Yrama Widya.

Gurol, A. (2011) 'Determining the reflective thinking skills of pre-service teachers in learning and teaching process', Energy Education Science and Technology Part B: Social and Educational Studies, 3(3), pp. 387-402.

Hidajat, F. A. et al. (2019) 'Exploration of Students' Arguments to Identify Perplexity from Reflective Process on Mathematical Problems', International Journal of Instruction, 12(2), pp. 573-586. doi: 10.29333/iji.2019.12236a.

Lee, H.-J. (2005) 'Understanding and assessing preservice teachers' reflective thinking', Teaching and Teacher Education, 21(6), pp. 699-715. doi: 10.1016/j.tate.2005.05.007.

Mitasari, Z. and Prasetiyo, N. A. (2016) 'Penerapan Metode Diskusi-Presentasi Dipadu Analisis Kritis Artikel melalui Lesson Study untuk Meningkatkan Pemahaman 
Konsep, Kemampuan Berpikir Kritis, dan Komunikasi’, Jurnal Bioedukatika, 4(1), pp. 11-14. doi: 10.26555/bioedukatika.v4i1.4736.

Rusman (2013) Model-Model Pembelajaran: Mengembangkan Profesionalisme Guru. Jakarta: PT Rajagrafindo Persada.

Subanji (2013) Pembelajaran Matematika Kreatif dan Inovatif. Malang: Universitas Negeri Malang (UM PRESS).

Sukaesih, S. and Alimah, S. (2012) 'Penerapan Praktek Pembelajaran Bermakna Berbasis Better Teaching Learning (Btl) Pada Mata Kuliah Microteaching Untuk Mengembangkan Kompetensi Profesional Calon Guru', Jurnal Penelitian Pendidikan, 29(2), pp. 165-172. doi: 10.15294/jpp.v29i2.5658.

Zehavi, N. and Mann, G. (2005) 'Instrumented Techniques and Reflective Thinking in Analytic Geometry', The Mathematics Enthusiast, 2(2), pp. 83-92. 